ECCOMAS

Proceedia
COMPDYN 2017

$6^{\text {th }}$ ECCOMAS Thematic Conference on Computational Methods in Structural Dynamics and Earthquake Engineering M. Papadrakakis, M. Fragiadakis (eds.) Rhodes Island, Greece, 15-17 June, 2017

\title{
ACCURACY OF EQUIVALENT LINEAR MODELS FOR BILINEAR OSCILLATORS UNDER PULSE-LIKE GROUND MOTION
}

\author{
Giuseppe Quaranta ${ }^{1}$ Fabrizio Mollaioli $^{2}$ \\ ${ }^{1}$ Department of Structural and Geotechnical Engineering, Sapienza University of Rome \\ via Eudossiana 18, 00184 Rome, Italy \\ e-mail: giuseppe.quaranta@uniroma1.it \\ ${ }^{2}$ Department of Structural and Geotechnical Engineering, Sapienza University of Rome \\ via Gramsci 53, 00197 Rome, Italy \\ e-mail: fabrizio.mollaioli@uniroma1.it
}

Keywords: Bilinear system, Equivalent viscous damping, Pulse-like ground motion.

\begin{abstract}
Nonlinear dynamic analysis is the most reliable approach for the assessment of structures under earthquake, provided that implemented computational method and adopted mechanical models are able to simulate properly material and geometrical nonlinearities. Nonetheless, several guidelines and codes also strive to include simplified methodologies for use in practice. In this perspective, several equivalent linear models have been proposed so far in order to allow a rapid analysis of oscillators with bilinear-type response, but none of the existing studies has yet examined systematically their reliability in case of pulse-like ground motion. Therefore, this paper presents the results of an extensive numerical investigation that aims at assessing whether existing equivalent linear models can be exploited in order to estimate the maximum displacement of bilinear oscillators under pulse-like near-fault ground motion. Several nonlinear dynamic analyses have been performed and final results demonstrate that the accuracy of current equivalent linear models depends on the ratio between the elastic period of the bilinear oscillator and the pulse period of the seismic excitation.
\end{abstract}




\section{INTRODUCTION}

Modern advances in structural modeling make nonlinear dynamic analysis a reliable methodology for the seismic assessment of structures (see for instance Refs. [1-3]), but the use of equivalent linear models is still very popular. The underlying idea of the equivalent linearization is to use a linear dynamic model which period and damping are calibrated in such a way to capture one or main features of the original nonlinear system's response as best as possible. Current approaches for deriving the equivalent linear properties are based on stochastic or deterministic analyses, see for instance Refs. [4-7] for an overview about some recent equivalent linear models of single-degree-of-freedom (SDOF) bilinear oscillators. Within this framework, it is worth highlighting that existing equivalent linear models for bilinear oscillators were developed without considering explicitly pulse-like near-fault ground motions, which seismological characteristics are different from the properties typically observed in case of far-field seismic events. In fact, several strong motion records obtained in recent earthquakes at sites close to the seismic causative fault exhibited a noticeable variability in the damage potential [8-10]. The reasons of this variability are the proximity of the source and the occurrence of forward directivity effects. Forward directivity refers to the strengthening of ground motion at sites located in the direction of the predominant rupture propagation, because it produces strong motions near the earthquake ruptures that often have a pulse-like waveform. Specifically, most of the energy originating from the source develops in a coherent, high-velocity pulse of moderate-to-long duration, with the strongest motion usually polarized in the direction normal to the fault [11]. The seismic protection of structures under pulse-like near-fault ground motions has been also addressed in the last years [12]. For instance, several researches have studied the effectiveness of seismic isolation systems, and they shown that base-isolated buildings can be vulnerable to large pulse-like ground motions generated at near-fault locations $[11,13]$. The main motivation is the large displacement undergone by seismic isolation devices for long period pulses associated in the near-fault motion. With these premises, the present work aims at investigating the accuracy of a recent equivalent linear model in predicting the maximum displacement of bilinear oscillators under pulse-like near-fault ground motion. Several numerical analysis have been performed and final results demonstrate that the accuracy of current equivalent linear models depends on the ratio between the elastic period of the bilinear oscillator and the pulse period of the seismic excitation.

\section{EQUIVALENT LINEARIZATION OF BILINEAR OSCILLATORS}

\subsection{Dynamics of a bilinear oscillator}

The dynamic behavior of a bilinear SDOF oscillator subjected to seismic base accelaration is descrived by the following system of differential equations with zero initial conditions [4]:

$$
\begin{gathered}
\ddot{x}(t)+2 \xi \omega_{n} \dot{x}(t)+\alpha \omega_{n}^{2} x(t)+\omega_{n}^{2}(1-\alpha) f_{1}\left(\dot{x}(t), z(t), x_{y}\right)=-\ddot{x}_{g}(t) \\
\dot{z}(t)=\dot{x}(t) f_{2}\left(\dot{x}(t), z(t), x_{y}\right)
\end{gathered}
$$

with

$$
\begin{aligned}
f_{1}\left(\dot{x}(t), z(t), x_{y}\right)= & z(t) f_{2}\left(\dot{x}(t), z(t), x_{y}\right)+ \\
& x_{y}\left(\mathcal{U}\left\{z(t)-x_{y}\right\} \mathcal{U}\{\dot{x}(t)\}-\right. \\
& \left.\mathcal{U}\left\{-z(t)-x_{y}\right\} \mathcal{U}\{-\dot{x}(t)\}\right),
\end{aligned}
$$




$$
\begin{aligned}
f_{2}\left(\dot{x}(t), z(t), x_{y}\right)= & 1-\mathcal{U}\left\{z(t)-x_{y}\right\} \mathcal{U}\{\dot{x}(t)\}- \\
& \mathcal{U}\left\{-z(t)-x_{y}\right\} \mathcal{U}\{-\dot{x}(t)\},
\end{aligned}
$$

where $x(t)$ is the displacement of the oscillator relative to the ground (the upper dots indicate the time-derivative), $\omega_{n}$ is the pre-yielding natural frequency (the pre-yielding natural period is $\left.T_{n}=2 \pi / \omega_{n}\right), \xi$ is the viscous damping, $\ddot{x}_{g}(t)$ is the seismic acceleration at the base of the oscillator, $\alpha$ is the hardening ratio (ratio of the post-yield over the pre-yield stiffness), $x_{y}$ is the yielding displacement (which is considered as positive numerical value) and $z(t)$ is an additional state variable. Moreover, $\mathcal{U}\{\nu\}$ is the Heaviside step function, i.e. $\mathcal{U}\{\nu\}=1$ for $\nu \geq 0$ and $\mathcal{U}\{\nu\}=0$ for $\nu<0$. It is understood that the dynamic response is symmetric. Bilinear SDOF oscillators with assigned displacement ductility will be considered. The displacement ductility is defined as $\mu=x^{\max } / x_{y}$, where $x^{\max }$ is the maximum absolute displacement undergone by the oscillator under the base acceleration $\ddot{x}_{g}(t)$.

\subsection{Some equivalent viscous damping formulations}

Linearized models for Eq. (1) are obtained by estimating the properties of a linear damped oscillator equivalent, in some sense, to the original dynamic system (the maximum absolute displacement criterion is here considered). These properties are the equivalent elastic period $T_{e q}$ and the equivalent viscous damping $\xi_{e q}$. The following short review is limited to linear equivalent models for bilinear SDOF systems in which the concept of secant stiffness is employed to determine $T_{e q}$, and thus:

$$
T_{e q}=T_{n} \sqrt{\frac{\mu}{1+\alpha(\mu-1)}} .
$$

The equivalent viscous damping $\xi_{e q}$ usually consists of two contributes, namely the inherent viscous damping of the original system $\xi$ and an additive-type correction. A popular formulation for the equivalent viscous damping of bilinear oscillators is due to Jacobsen [14], which reads:

$$
\xi_{e q}=\xi+\frac{2(1-\alpha)(\mu-1)}{\pi \mu[1+\alpha(\mu-1)]}
$$

It can be observed that Eq. (4) does not depend on the elastic period $T_{n}$. Another common formulation of $\xi_{e q}$ for bilinear models - which depends on $T_{n}$ - is [15]:

$$
\xi_{e q}=\xi+\frac{1.230}{\pi}\left(1-\frac{1}{\sqrt{\mu}}-0.1 \alpha \mu\right)\left[1+\frac{1}{\left(T_{e q}+0.85\right)^{4}}\right] .
$$

The functional form given by Eq. (4) has been modified by Liu and co-workers in a series of recent papers. Specifically, the following formulation is presented in Ref. [6]:

$$
\xi_{e q}=\xi+\frac{2(1-\alpha)(\mu-1)}{\pi \mu[1+\alpha(\mu-1)]} \frac{1}{\left(0.7763+0.2886 T_{n}\right)+\frac{0.5651+1.8410 T_{n}}{e^{\alpha \mu}}} .
$$

More recently, Liu and co-workers have calibrated another formulation for $\xi_{e q}$, which reads [7]:

$$
\xi_{e q}=\xi+\frac{2(1-\alpha)(\mu-1)}{\pi \mu[1+\alpha(\mu-1)]}\left[A T_{n}^{B}(\mu-1)^{C}\right],
$$


where

$$
\begin{gathered}
A=0.8124-\frac{0.08534}{\alpha+0.1461}, \\
B=-0.1285-\frac{0.003477}{\alpha+0.006828}, \\
C=\frac{0.06979 \alpha-0.00003018}{\alpha^{2}+0.2463 \alpha+0.001524} .
\end{gathered}
$$

The authors have shown that Eq. (7) outperforms the models proposed by Refs. $[6,14,15]$ in predicting the maximum displacement of bilinear oscillators. Therefore, Eq. (7) will be considered as reference model of the equivalent viscous damping for the following analyses. Overall, recent equivalent viscous damping usually depends on the hardening ratio $\alpha$, the displacement ductility $\mu$ and the elastic period $T_{n}$. None of these models takes into account the features of the seismic ground motion.

\section{ACCURACY OF THE EQUIVALENT LINEAR MODEL}

\subsection{Selected pulse-like accelerograms}

The list of 30 near-fault pulse-like accelerograms adopted in this numerical study is given in Appendix (Table 1). They are a subset of the accelerograms listed in Ref. [12]. This list collects 6 bins (each of them including 5 accelerograms), according to the pulse period $T_{p}$. The following ranges of $T_{p}$ are considered: i) $T_{p} \leq 1 \mathrm{~s}$; ii) $1 \mathrm{~s}<T_{p} \leq 2 \mathrm{~s}$; iii) $2 \mathrm{~s}<T_{p} \leq 3 \mathrm{~s}$; iv) $\left.3 \mathrm{~s}<T_{p} \leq 4 \mathrm{~s} ; \mathrm{v}\right) 4 \mathrm{~s}<T_{p} \leq 5 \mathrm{~s}$; vi) $T_{p}>5 \mathrm{~s}$.

\subsection{Solution of the motion equation and numerical data of the bilinear oscillators}

In this study, the motion equation given by Eq. (1) is solved by means of the Runge-Kutta technique (ode 45 MATLAB function). Oscillators were forced to deform to the specifed ductility $\mu$ using the iterative approach presented in Ref. [16]. Therefore, once a preliminary estimate of the yielding displacement is assumed, the peak displacement is calculated by solving Eq. (1) and the ductility is obtained. Iterations are then carried out on the yielding displacement until the difference between target ductility and computed ductility is less than $0.5 \%$ the target ductility. The estimate of the yielding displacement at the beginning of the iterative procedure is here obtained by dividing the maximum absolute displacement calculated through the equivalent linear model in Ref. [7] by the target ductility. The following numerical values are considered for the nonlinear time-history analyses:

- pre-yielding natural periods $T_{n}$ beween $0.05 \mathrm{~s}$ and $1.50 \mathrm{~s}$ with constant step equal to 0.05 $\mathrm{s}$, between $1.50 \mathrm{~s}$ and $3.50 \mathrm{~s}$ with constant step equal to $0.10 \mathrm{~s}$, between $3.50 \mathrm{~s}$ and $6.00 \mathrm{~s}$ with constant step equal to $0.25 \mathrm{~s}$, between $6.00 \mathrm{~s}$ and $11.00 \mathrm{~s}$ with constant step equal to $0.50 \mathrm{~s}$;

- null viscous damping, as in Ref. [7];

- hardening ratios $\alpha$ equal to $0.00,0.05,0.10,0.20$;

- displacement ductility $\mu$ equal to $1.5,2.0,3.0,4.0,5.0,6.0$.

The range of values of $T_{n}$ is selected to facilitate the parametric analysis of the linearized model with respect to the ratio $T_{n} / T_{p}$ for each value of $T_{p}$. On the other hand, numerical values of 
$\alpha$ and $\mu$ are representative of most bilinear-like behaviors of interest for structural engineering applications.

\subsection{Accuracy index}

The accuracy of the equivalent linear model is evaluated in terms of maximum absolute displacement. To this end, the following displacement error index is considered:

$$
E_{d}=\frac{x_{e q}^{\max }}{x^{\max }},
$$

where $x_{e q}^{\max }$ is the maximum absolute displacement of the equivalent linear model. Numerical values of $E_{d}$ close to 1 indicate that the equivalent linear model is able to predict the maximum absolute displacement of the bilinear oscillator.

\subsection{Assessment of existing linearized model}

The accuracy of the equivalent linear model proposed by Liu et al. [7] is now assessed with reference to pulse-like near-fault ground motions. It is important to remark that the equivalent viscous damping calibrated in Ref. [7] was obtained with no specific assumptions about the earthquake type. Moreover, the largest pre-yielding natural period in the present study is equal to $11 \mathrm{~s}$, and it is much larger than the maximum value assumed in Ref. [7] (which is equal to 1.5 s). On the contrary, hardening ratio and displacement ductility values assumed in the present numerical study are compatible with the values adopted in Ref. [7]. All these considerations should be properly taken into account when examining the following results.

Numerical values of the displacement error index $E_{d}$ as function of the dimensionless elastic period $T_{n} / T_{p}$ are shown in Figure 1 (for $T_{p} \leq 1 \mathrm{~s}$ ), Figure 2 (for $1 \mathrm{~s}<T_{p} \leq 2 \mathrm{~s}$ ), Figure 3 (for $2 \mathrm{~s}<T_{p} \leq 3 \mathrm{~s}$ ), Figure 4 (for $3 \mathrm{~s}<T_{p} \leq 4 \mathrm{~s}$ ), Figure 5 (for $4 \mathrm{~s}<T_{p} \leq 5 \mathrm{~s}$ ) and Figure 6 (for $T_{p}>5 \mathrm{~s}$ ). All these figures clearly show that the accuracy of the equivalent linearizion depends on the ratio between the elastic period of the bilinear oscillator and the pulse period of the near-fault earthquake. Specifically, the greater is the value of the ratio $T_{n} / T_{p}$, the better is the accuracy. Indeed, the linearization error becomes smaller (i.e., $E_{d} \rightarrow 1$ ) for oscillators which elastic period $T_{n}$ is large compared to the pulse period $T_{p}$ of the earthquake ground motion. Conversely, the use of the linear equivalent model for oscillators which elastic period $T_{n}$ is low compared to the pulse period $T_{p}$ might produce large errors in the assessment of the maximum displacement response for bilinear-type systems. The linearization error of the considered equivalent model is not significantly biased by the displacement ductility value while the discrepancy reduces as the hardening ratio increases. Mean and standard deviation of the displacement errors $E_{d}$ have been also calculated for each accelerogram. The confidence intervals of the displacement error index $E_{d}$ for each pulse period $T_{p}$ and hardening ratio $\alpha$ are shown in Figure 7. The trend of the mean displacement error is highlighted in Figure 8. In average, the larger is the pulse period $T_{p}$, the larger is the displacement error index (see regression lines in Figure 8). An increment of the hardening ratio $\alpha$ reduces the standard deviation values. 

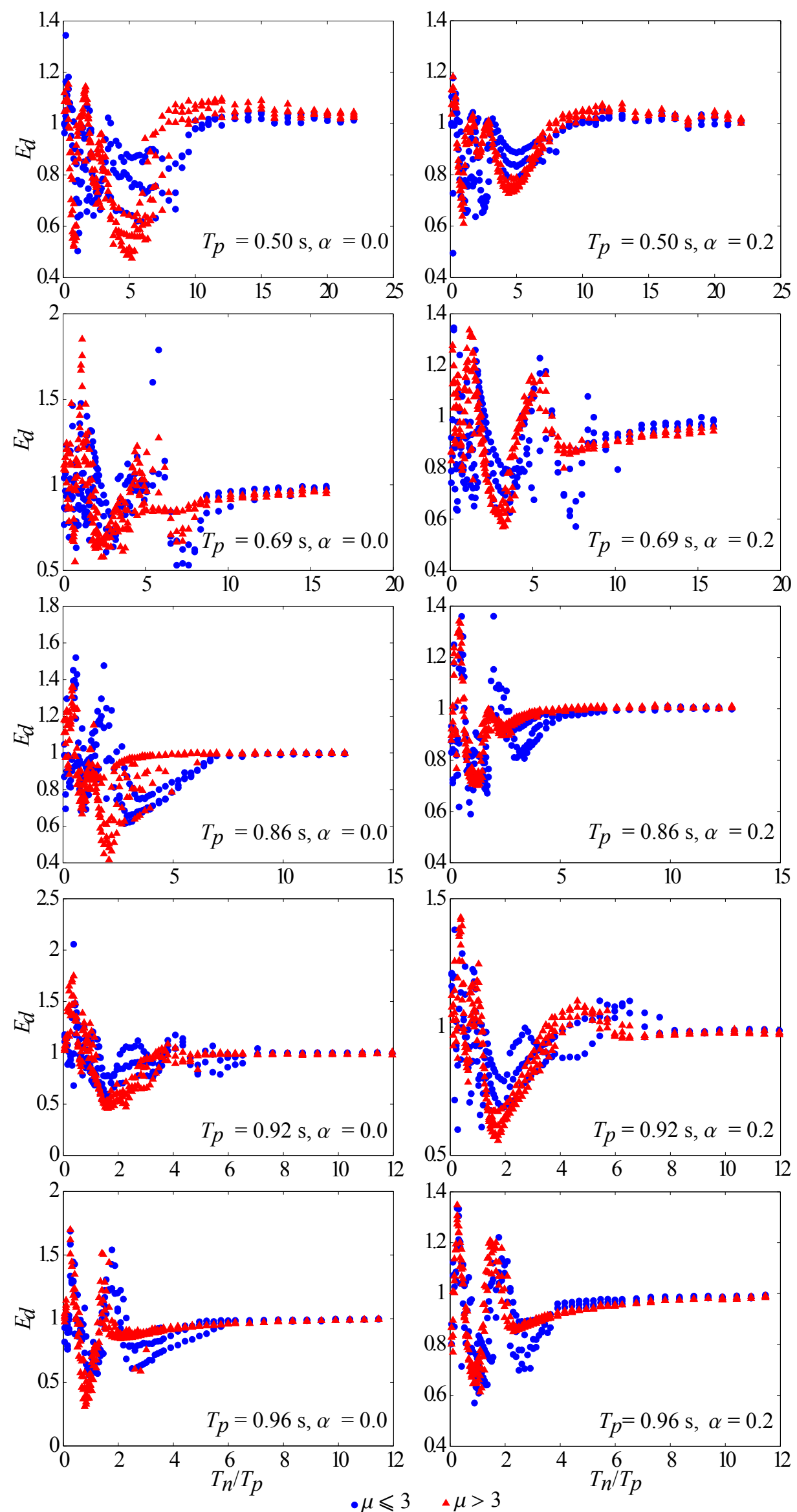

Figure 1: Displacement error values $E_{d}$ for $T_{p} \leq 1 \mathrm{~s}$. 

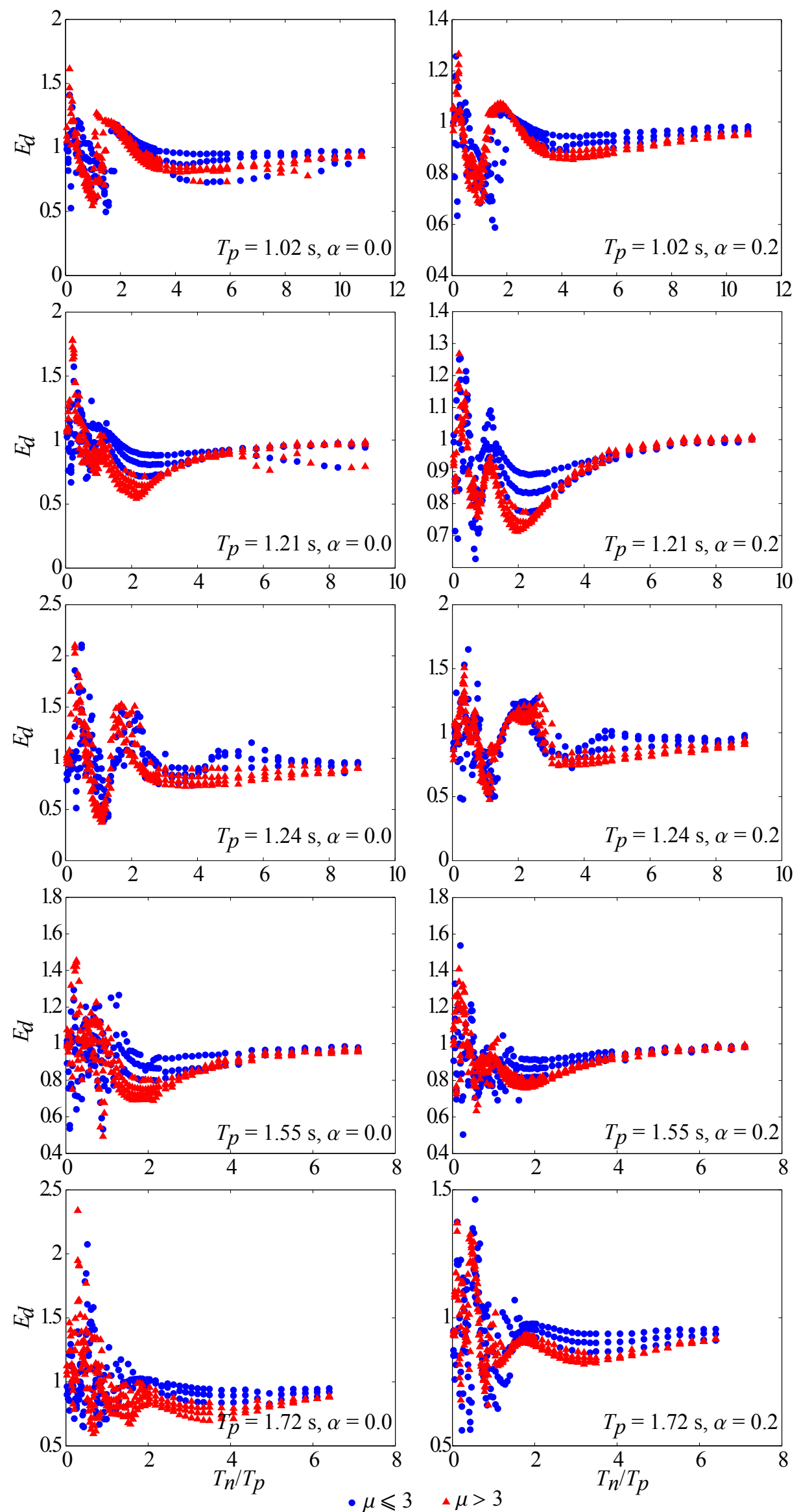

Figure 2: Displacement error values $E_{d}$ for $1 \mathrm{~s}<T_{p} \leq 2 \mathrm{~s}$. 

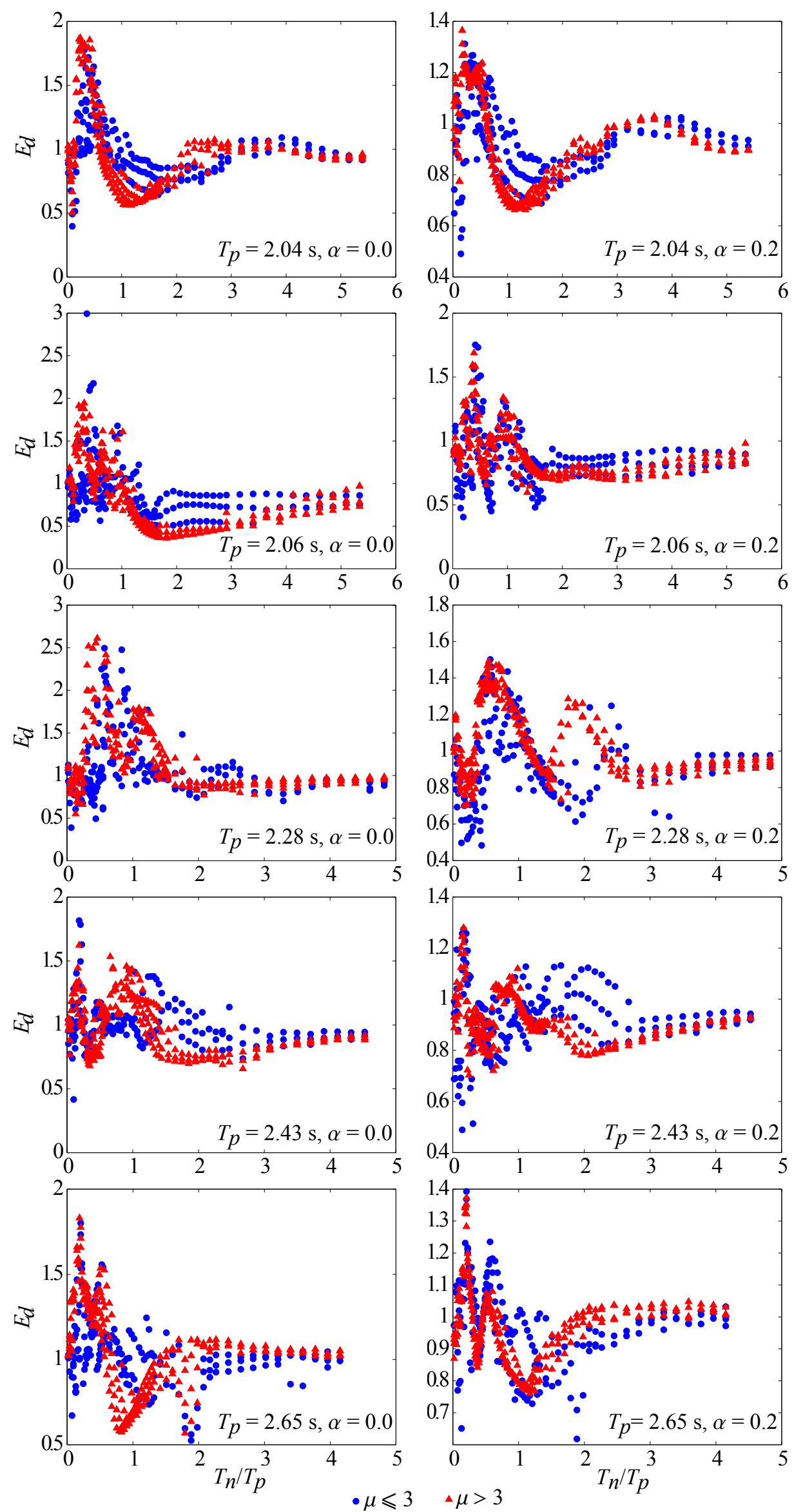

Figure 3: Displacement error values $E_{d}$ for $2 \mathrm{~s}<T_{p} \leq 3 \mathrm{~s}$. 

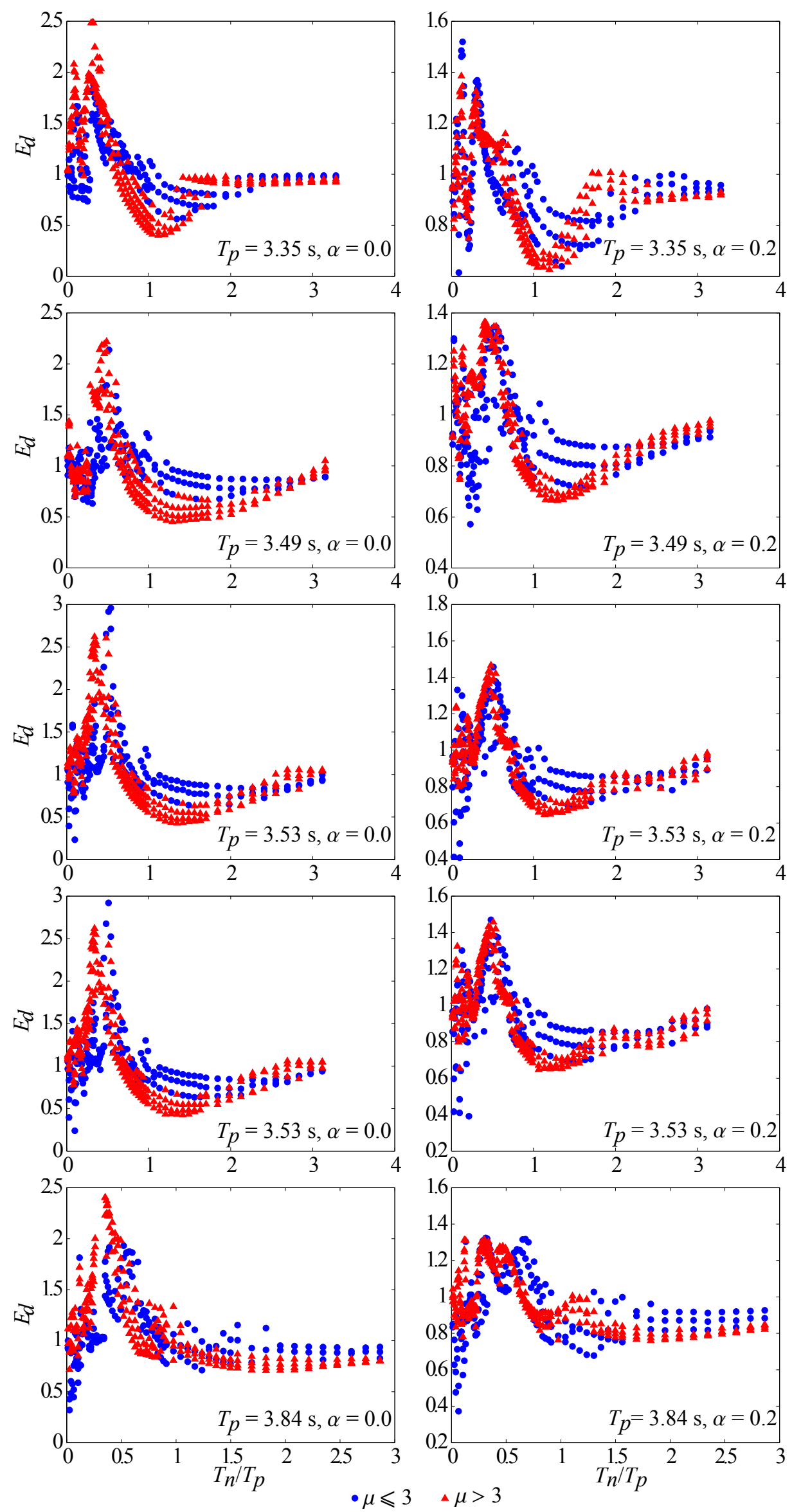

Figure 4: Displacement error values $E_{d}$ for $3 \mathrm{~s}<T_{p} \leq 4 \mathrm{~s}$. 

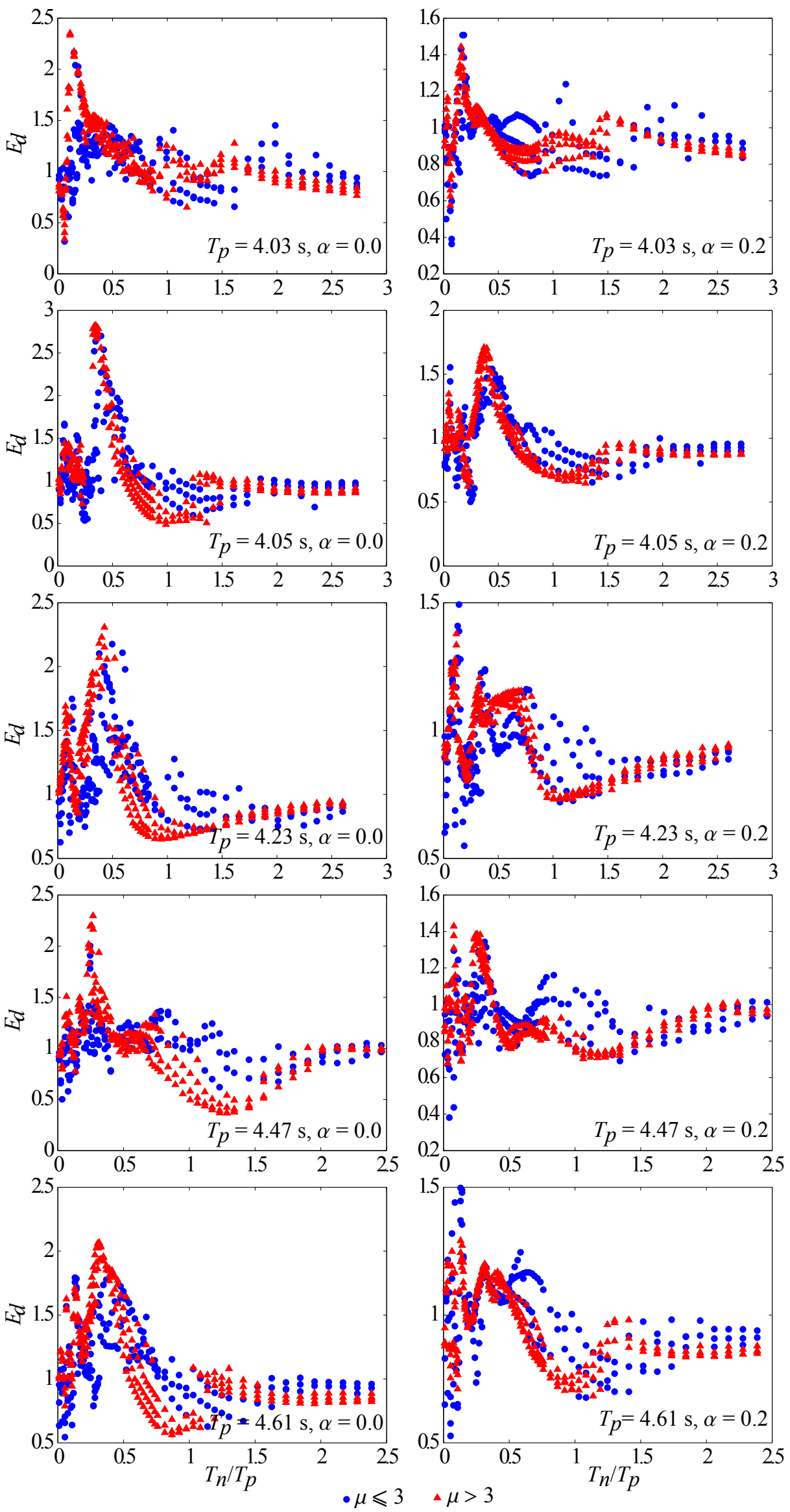

Figure 5: Displacement error values $E_{d}$ for $4 \mathrm{~s}<T_{p} \leq 5 \mathrm{~s}$. 

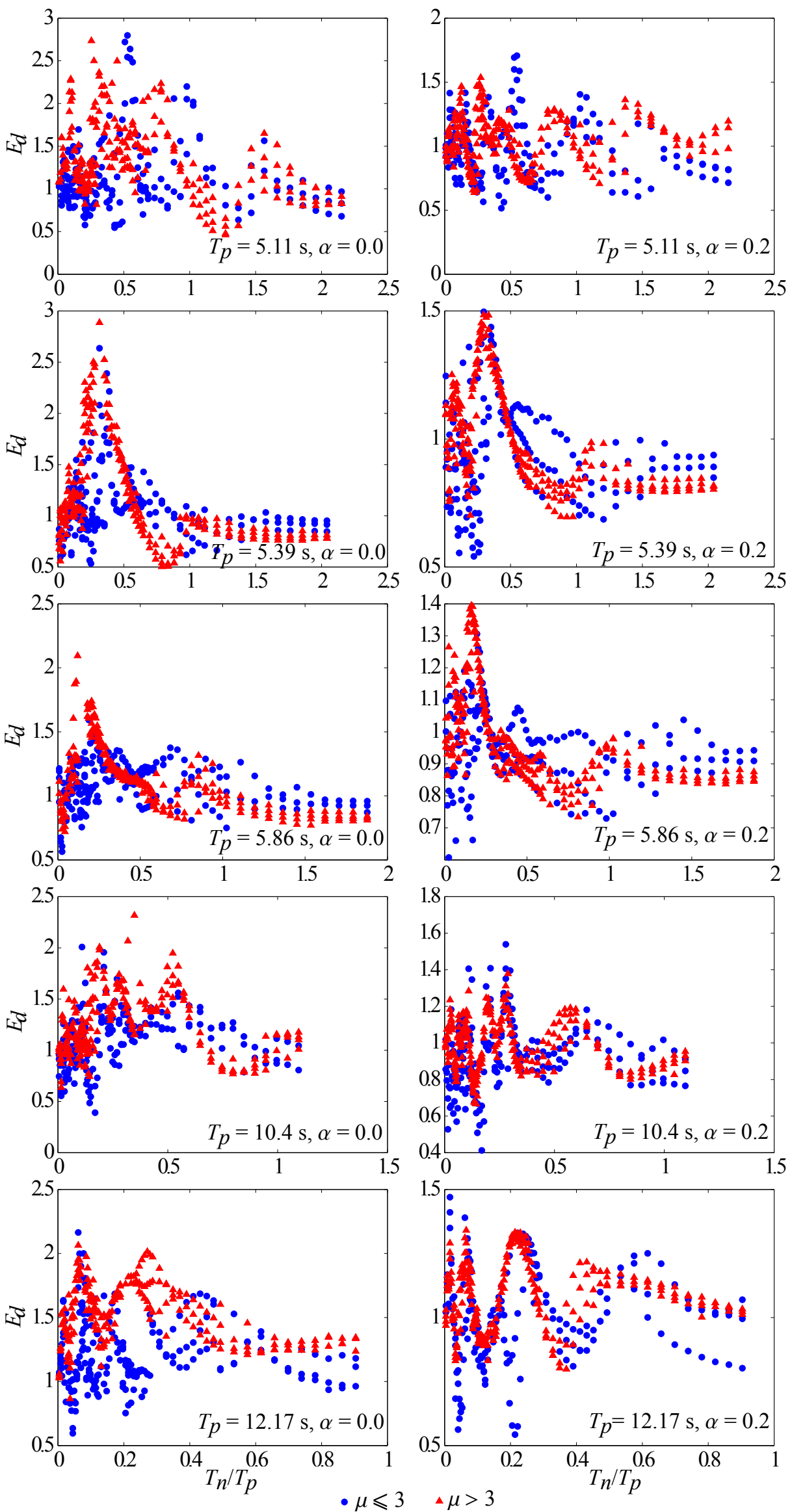

Figure 6: Displacement error values $E_{d}$ for $T_{p}>5 \mathrm{~s}$. 

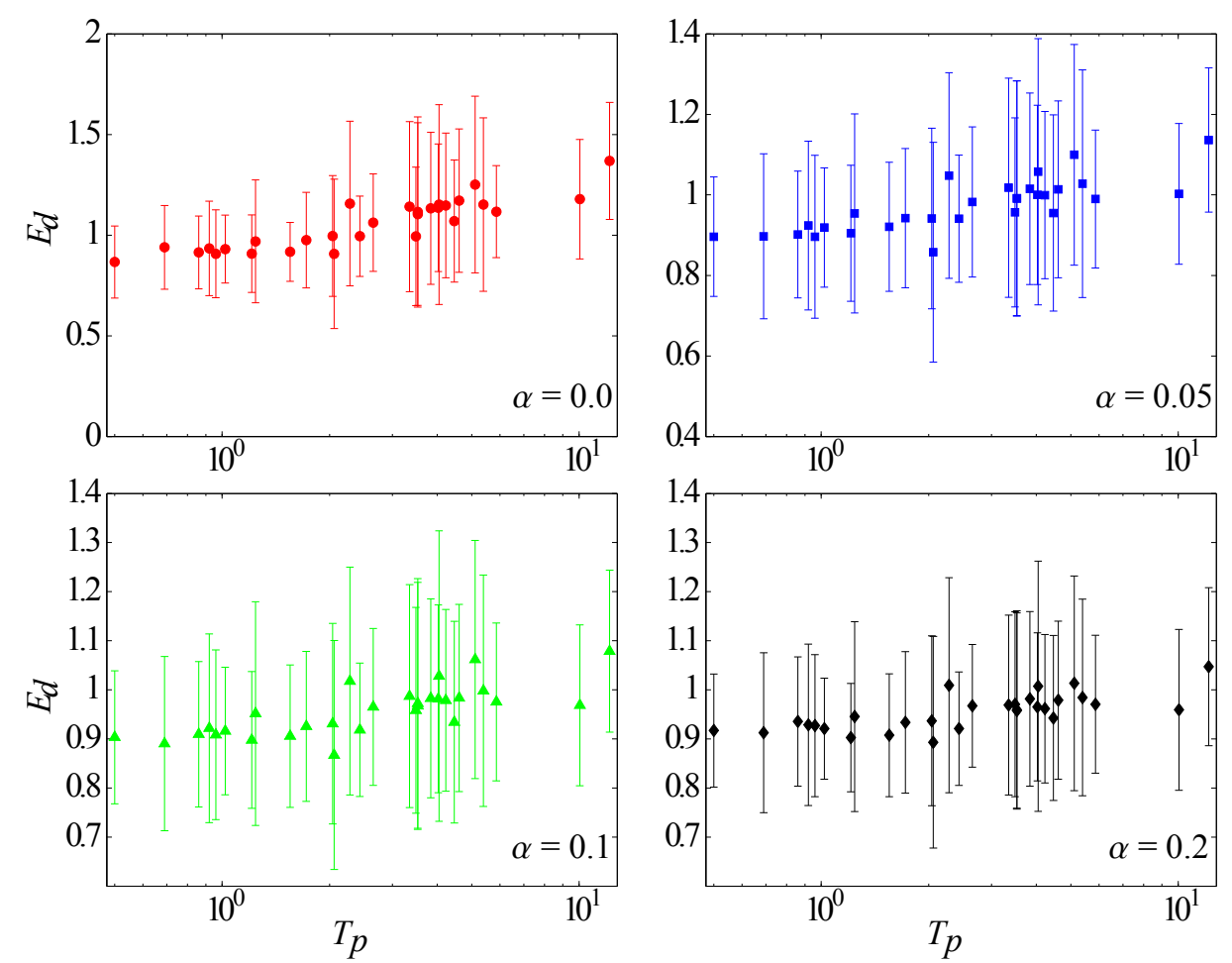

Figure 7: Confidence interval of the displacement error $E_{d}$ for each pulse period $T_{p}[\mathrm{~s}]$ and hardening ratio $\alpha$ (the central dot indicates the mean value whereas the vertical error bar is two standard deviation units in length).

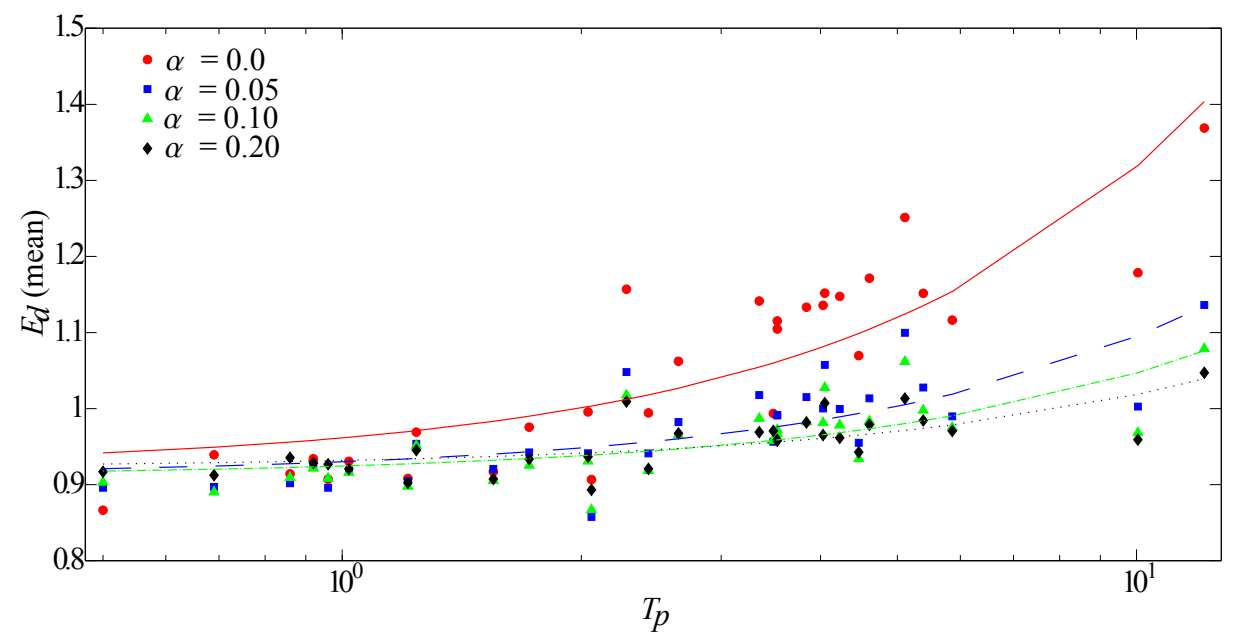

Figure 8: Trend of the mean displacement error for each pulse period $T_{p}[\mathrm{~s}]$ and hardening ratio $\alpha$ (the dots indicate the mean value of $E_{d}$ whereas the continuos line is the corresponding linear regression).

\section{CONCLUSIONS}

The present work has investigated the accuracy of an equivalent linear model for the estimation of the maximum displacement of bilinear oscillators under pulse-like near-fault ground motion. Final results have demonstrated that the accuracy of the equivalent linearization depends on the ratio between the elastic period of the bilinear oscillator $T_{n}$ and the pulse period 
$T_{p}$ of the near-fault earthquake. Specifically, it has been found that the use of a linear equivalent model for bilinear oscillators which elastic period $T_{n}$ is low compared to the pulse period $T_{p}$ might produce large errors. These results suggest that an improved estimation can be obtained by taking into account the pulse period $T_{p}$ of the seismic base motion.

\section{ACKNOWLEDGMENTS}

The authors acknowledge the support from Sapienza University of Rome through the project "Smart solutions for the assessment of structures in seismic areas". Their work is also framed within the research project DPC-ReLUIS 2017.

\section{APPENDIX}

\begin{tabular}{l|c|c|c}
\hline Earthquake & Magnitude & PGA $[g]$ & $T_{p}[\mathrm{~s}]$ \\
\hline Parkfield, 2004 & 6.00 & 0.6464 & 0.50 \\
Coalinga-05, 1983 & 5.77 & 0.8661 & 0.69 \\
San Salvador, 1986 & 5.80 & 0.8456 & 0.86 \\
Coalinga-05, 1983 & 5.77 & 0.8595 & 0.92 \\
San Salvador, 1986 & 5.80 & 0.4205 & 0.96 \\
\hline Parkfield, 2004 & 6.00 & 0.4373 & 1.02 \\
Coyote Lake, 1979 & 5.74 & 0.4521 & 1.21 \\
Morgan Hill, 1984 & 6.19 & 0.2435 & 1.24 \\
N. Palm Springs, 1986 & 6.06 & 0.3291 & 1.55 \\
Loma Prieta, 1989 & 6.93 & 0.4062 & 1.72 \\
\hline Bam, 2003 & 6.50 & 0.8501 & 2.04 \\
Kobe, 1995 & 6.90 & 0.3229 & 2.06 \\
Irpinia, 1980 & 6.90 & 0.2321 & 2.28 \\
Westmorland, 1981 & 5.90 & 0.4121 & 2.43 \\
Erzican, 1992 & 6.69 & 0.4864 & 2.65 \\
\hline Imperial Valley-06, 1979 & 6.53 & 0.3780 & 3.35 \\
Northridge-01, 1994 & 6.69 & 0.8387 & 3.49 \\
Northridge-01, 1994 & 6.69 & 0.5178 & 3.53 \\
Northridge-01, 1994 & 6.69 & 0.5179 & 3.53 \\
Imperial Valley-06, 1979 & 6.53 & 0.4417 & 3.84 \\
\hline Imperial Valley-06, 1979 & 6.53 & 0.1580 & 4.03 \\
Imperial Valley-06, 1979 & 6.53 & 0.3754 & 4.05 \\
Imperial Valley-06, 1979 & 6.53 & 0.4624 & 4.23 \\
Loma Prieta, 1989 & 6.93 & 0.3627 & 4.47 \\
Imperial Valley-06, 1979 & 6.53 & 0.3571 & 4.61 \\
\hline Kocaeli, 1999 & 7.51 & 0.2832 & 5.11 \\
Imperial Valley-06, 1979 & 6.53 & 0.4680 & 5.39 \\
Imperial Valley-06, 1979 & 6.53 & 0.4172 & 5.86 \\
Chi-Chi, 1999 & 7.62 & 0.2178 & 10.04 \\
Chi-Chi, 1999 & 7.62 & 0.5621 & 12.17 \\
\hline
\end{tabular}

Table 1: List of pulse-like near-fault accelerograms (PGA: peak ground acceleration, $T_{p}$ : pulse period). 


\section{REFERENCES}

[1] A. Scodeggio, G. Quaranta, G.C. Marano, G. Monti, R. B. Fleischman, Optimization of force-limiting seismic devices connecting structural subsystems. Computers and Structures, 162, 16-27, 2016.

[2] G. Quaranta, G.C. Marano, R. Greco, G. Monti, Parametric identification of seismic isolators using differential evolution and particle swarm optimization. Applied Soft Computing, 22, 458-464, 2014.

[3] G. Quaranta, G. Monti, G. C. Marano, Parameters identification of Van der Pol-Duffing oscillators via particle swarm optimization and differential evolution. Mechanical Systems and Signal Processing, 24(7), 2076-2095, 2010.

[4] P.D. Spanos, A. Giaralis, Third-order statistical linearization-based approach to derive equivalent linear properties of bilinear hysteretic systems for seismic response spectrum analysis. Structural Safety, 44, 59-69, 2013.

[5] T. Zordan, T. Liu, B. Briseghella, Q. Zhang, Improved equivalent viscous damping model for base-isolated structures with lead rubber bearings. Engineering Structures, 75, 340$352,2014$.

[6] T. Liu, T. Zordan, B. Briseghella, Q. Zhang, An improved equivalent linear model of seismic isolation system with bilinear behavior. Engineering Structures, 61, 113-126, 2014.

[7] T. Liu, T. Zordan, Q. Zhang, B. Briseghella, Equivalent viscous damping of bilinear hysteretic oscillators. Journal of Structural Engineering, 141(11), 06015002, 2015.

[8] J.D. Bray, A. Rodriguez-Marek, Characterization of forward-directivity ground motions in the near-fault region. Soil Dynamics and Earthquake Engineering, 24(11), 815-828, 2004.

[9] F. Mollaioli, S. Bruno, L.D. Decanini, G.F. Panza, Characterization of the dynamic response of structures to damaging pulse-type near-fault ground motions. Meccanica, 41(1), 23-46, 2006.

[10] E. Kalkan, S.K. Kunnath, Effects of fling step and forward directivity on seismic response of buildings. Earthquake Spectra, 22(2), 367-390, 2006.

[11] J.F. Hall, T.H. Heaton, M.W. Halling, D.J. Wald, Near-source ground motion and its effects on flexible buildings. Earthquake Spectra, 11(4), 569-605, 1995.

[12] G. Quaranta, F. Mollaioli, G. Monti, Effectiveness of design procedures for linear TMD installed on inelastic structures under pulse-like ground motion. Earthquakes and Structures, 10(1), 239-260, 2016.

[13] T.H. Heaton, J.F. Hall, D.J. Wald, M.W. Halling, Response of high-rise and base-isolated buildings to a hypothetical Mw 7.0 blind thrust earthquake. Science, 267(5195), 206-211, 1995.

[14] L.S. Jacobsen, Steady forced vibrations as influenced by damping. ASME Transactions, 52(1), 169-181, 1930. 
[15] C.A. Blandon, M.J.N. Priestley, Equivalent viscous damping equations for direct displacement based design. Journal of Earthquake Engineering, 9(sup2), 257-278, 2005.

[16] G.A. MacRae, K. Kawashima, Post-earthquake residual displacements of bilinear oscillators. Earthquake Engineering \& Structural Dynamics, 26(7), 701-716, 1997. 